\title{
Neo-Thomism and the Problem of Animal Suffering ${ }^{1}$
}

\author{
B. Kyle KeLtZ \\ South Plains College \\ Levelland, $T X$
}

\begin{abstract}
A moral being is one who is capable of reflecting on his past actions and their motives - of approving of some and disapproving of others; and the fact that man is the one being who certainly deserves this designation, is the greatest of all distinctions between him and the lower animals.
\end{abstract}

Charles Darwin ${ }^{2}$

It has been over ten years since Michael Murray and Glenn Ross published their article "Neo-Cartesianism and the Problem of Animal Suffering." ${ }^{3}$ The arguments in that article later served as a major aspect of Murray's defense of theism in his work on the problem of animal suffering titled Nature Red in Tooth and Claw: Theism and the Problem of Animal Suffering. ${ }^{4}$ Murray's book was especially significant at the time because few, if any, monographs had been published covering the problem of animal suffering. ${ }^{5}$

1 I am grateful to Michael J. Murray, J. Thomas Bridges, and an anonymous reviewer for their helpful comments on previous versions of this essay.

2 Charles Darwin, Descent of Man, 2nd ed. (Amherst, NY: Prometheus Books, 1998 [originally 1874]), 633.

3 Michael J. Murray and Glenn Ross, "Neo-Cartesianism and the Problem of Animal Suffering," Faith and Philosophy 23 (2006): 169-90.

4 Michael J. Murray, Nature Red in Tooth and Claw: Theism and the Problem of Animal Suffering (New York: Oxford University Press, 2008).

5 Christopher Southgate's work was published the same year: The Groaning of 
The argument in "Neo-Cartesianism and the Problem of Animal Suffering," inspired by René Descartes, emphasizes that there is no evidence proving that nonhuman animals phenomenologically experience pain. Murray and Ross argue that, although some nonhuman animals have physiological systems that are analogous to the systems in humans that make the phenomenological experience of pain possible, there is no evidence necessitating the conclusion that nonhuman animals do phenomenologically experience pain. ${ }^{6}$

They suggest it is possible that nonhuman animals exhibit pain-averse behaviors even though they might not phenomenologically experience pain. Murray and Ross mention that it does not seem that the actual awareness of pain would add to the evolutionary advantage of pain-avoiding behaviors. ${ }^{7}$ Thus, if one has good reasons to believe that theism is true, then there is room to believe that nonhuman animals do not phenomenologically experience pain, since it would seem that God would not allow them to do so. ${ }^{8}$

Murray's and Ross's article is significant regarding the problem of animal suffering in that, if nonhuman animals do not phenomenologically experience pain, then there is no problem of animal suffering. However, few scholars have found the neo-Cartesian position compelling. Many, including theists, have argued that neo-Cartesian arguments fail and that the problem of animal suffering still stands.

Indeed, some theists have even argued that the problem is probably worse than many have thought. ${ }^{10}$ So, although there have been a few other major attempts at defending theism from the problem of animal suffering (involving evolutionary and soul-making theodicies), it seems that theists

Creation: God, Evolution, and the Problem of Evil (Louisville, KY: Westminster John Knox Press, 2008).

6 Murray and Ross emphasize that they do not necessarily believe that neo-Cartesianism is true, but rather that the possibility of its truth is significant for the problem of animal suffering ( "Neo-Cartesianism," 186).

Murray and Ross, "Neo-Cartesianism," 177.

Murray and Ross, "Neo-Cartesianism," 171-72, 186.

For examples, see: Nicola Hoggard Creegan, Animal Suffering and the Problem of Evil (New York: Oxford University Press, 2013), 31-32, 51-53; Robert Francescotti, "The Problem of Animal Pain and Suffering," in The Blackwell Companion to the Problem of Evil, ed. Justin P. McBrayer and Daniel Howard-Snyder (Somerset, NJ: John Wiley and Sons, 2013), 114-21; and Trent Dougherty, The Problem of Animal Pain: A Theodicy for All Creatures Great and Small (New York: Palgrave Macmillan, 2014), 56-95.

10 See Dustin Crummett, "The Problem of Evil and the Suffering of Creeping Things," International Journal for Philosophy of Religion 82, no. 1 (2017): 171-88. 
have not been successful at providing compelling arguments against the problem of animal suffering. ${ }^{11}$

With this situation in mind, the present article attempts to provide a solution to the problem of animal suffering similar to Murray and Ross's neo-Cartesian arguments. Particularly, I will discuss a solution to the problem of animal suffering involving concepts taken from the medieval philosopher/theologian Thomas Aquinas. First, I will briefly discuss the problem of animal suffering and how the possible neo-Cartesian positions regarding nonhuman animal minds avoid the problem. These positions will help provide a contrast when I next describe Aquinas's positions regarding animal souls and human self-awareness. After describing the neo-Cartesian and Thomistic positions, I will discuss contemporary philosophical and scientific viewpoints regarding animal rationality, metacognition, and episodic memory. The contemporary evidence will help me to propose a neo-Thomistic view of animal minds in relation to the problem of animal suffering. After considering an objection, I will conclude that the neo-Thomistic view provides a more compelling alternative to the neo-Cartesian solution to the problem of animal suffering.

\section{Animal Minds and the Problem of Animal Suffering}

The problem of animal suffering slowly emerged over the years as modern science made discoveries regarding the age of the earth and the number of creatures that lived prior to the arrival of anatomically modern humans. Traditional answers to the problem of evil did not cover these new discoveries. For example, fossil remains indicating that animals lived and died much earlier than humans suggest that animals were dying and suffering before Adam and Eve could have sinned. This not only sheds doubt on

11 Creegan and Dougherty both reject neo-Cartesianism, but neither provides compelling alternatives. Creegan does not offer a theodicy because she thinks we may never fully understand why evil exists in creation (Animal Suffering, 55). Dougherty offers an animal soul-making theodicy in The Problem of Animal Pain that seems to contradict the very raison d'être of soul-making theodicies. For example, although Dougherty provides plenty of argumentation as to why God should resurrect animals in the eschaton, he does not explain how the earthly lives of animals can give rise to personality traits that cannot surface without the existence of actual or possible suffering (Michael J. Murray, review of The Problem of Animal Pain: A Theodicy for All Creatures Great and Small, by Trent Dougherty, International Journal for Philosophy of Religion 78 [2015]: 138). Elsewhere, Southgate makes little progress with arguments that he mentions are not necessarily meant to solve the problem of animal suffering, but merely to explain why God cannot prevent/eliminate animal suffering (The Groaning of Creation, 15-17). 
traditional Fall theodicies but also causes problems for free-will and soul-making theodicies. Indeed, before Darwin, theodicies seemed to be solely concerned with solving the problem of human suffering. In light of this, proponents of the problem of animal suffering emphasize that an all-good, all-knowing, and all-powerful God would most likely not include millions of years of animal suffering in the process by which he decided to create humanity. Thus, given the amount of animal suffering found in the earth's natural history, an all-good, all-knowing, and all-powerful God most likely does not exist.

\section{Neo-Cartesianism}

As mentioned, the neo-Cartesian answer to this problem is to deny that nonhuman animals are aware of any pain. If nonhuman animals lack phenomenological awareness of pain and suffering, then there can be no problem of animal suffering. Murray and Ross discuss four similar but different options from which neo-Cartesians can choose regarding animals and pain. (1) "Many non-human creatures are conscious inasmuch as they are alive, awake and have sensations.... Yet, unlike the sensory states possessed by humans, the mechanisms whereby these organisms have access to the world lack any phenomenal character whatsoever." 12 (2) "For a mental state to be a conscious state (phenomenally) requires an accompanying higher-order mental state (a HOT) that has that state as its intentional object.... Only humans have the cognitive faculties required to form the conception of themselves being in a first-order state that one must have in order to have a HOT."13 (3) "Some non-human creatures have states that have intrinsic phenomenal qualities analogous to those possessed by humans when they are in states of pain. These creatures lack, however, any higher-order states of being aware of themselves as being in first-order states." 14 and (4) "Most creatures lack the cognitive faculties required to be in a higher-order state of recognizing themselves to be in a first-order state of pain. Those [non-human creatures] that can on occasion achieve a second-order access to their first-order states of pain, nonetheless do not have the capacity to regard that second-order state as undesirable." ${ }^{15}$

So, more briefly, according to Murray and Ross, neo-Cartesianism entails that animals either (1) lack phenomenal consciousness, (2) lack the higher-order mental states required for phenomenal consciousness, (3) are

\footnotetext{
Murray and Ross, "Neo-Cartesianism," 175.

Murray and Ross, "Neo-Cartesianism," 176.

Murray and Ross, "Neo-Cartesianism," 176.

Murray and Ross, "Neo-Cartesianism," 177.
} 
phenomenally conscious of pain but lack higher-order mental states, or (4) are phenomenally aware of pain, with some having higher-order mental states regarding the pain but lacking the capacity to regard such higher states as undesirable. If any one of these four options were true, then the apparent suffering found in nature would be illusory and the problem of animal suffering would dissolve.

These four possible options are called neo-Cartesian because they draw inspiration from Descartes famous position regarding animal minds. Descartes's philosophy entails that the immaterial mind/soul provides human beings with the capacity for conscious mental states. ${ }^{16}$ Thus, if animals do not demonstrate the capacity for rational thought, then it seems they would lack both minds/souls and phenomenal consciousness. ${ }^{17}$ These four neo-Cartesian positions emphasize that there is no evidence necessitating the conclusion that animals possess phenomenal consciousness. Thus, they conclude that God's non-existence does not necessarily follow from the appearance of animal suffering.

\section{Thomism}

Thomas Aquinas is also famous for his position regarding animal minds. Following Aristotle, Aquinas believed that human beings possess rational souls while animals possess only sensitive souls. ${ }^{18}$ Humans are capable of consciousness and movement, as are other animals, but humans are the only animals with the abilities of the intellect and will. This crucial difference entails that nonhuman animals lack the ability to understand what they experience and are unable to act rationally:

In the souls of brute animals ... there is no operation superior to those of the sensitive part, since they neither understand nor reason. This is evident from the fact that all animals of the same species

16 René Descartes, Discourse on Method of Rightly Conducting the Reason, and Seeking the Truth in the Sciences, part IV.

17 Some of Descartes's writings indicate that his mature view regarding animals was closer to the Aristotelian/Thomistic view than to the view that many attribute to him (see Gary Steiner, "Descartes, Christianity, and Contemporary Speciesism," in A Communion of Subjects: Animals in Religion, Science, and Ethics, ed. Paul Waldau and Kimberly Patton [New York: Columbia University Press, 2006], 118-23, and John Cottingham, Descartes' Treatment of Animals," in Descartes, ed. John Cottingham [New York: Oxford University Press, 1998], 225-33). However, much of his philosophy entails that animals lack phenomenal consciousness.

18 For example, see Thomas Aquinas, Summa contra gentiles [SCG] II, ch. 60. 
operate in the same way, as though moved by nature and not as operating by art; every swallow builds its nest and every spider spins its web, in the same manner. The souls of brutes, then, are incapable of any operation that does not involve the body. ${ }^{19}$

As will be discussed below, the nonhuman-animal lack of intellect and will entails that they are not moral agents and that their suffering is not morally significant.

This might seem to be almost identical with the Cartesian position. ${ }^{20}$ Indeed, Cartesianism and Thomism are similar in that rationality serves in both as a criterion for moral agency and personhood. However, there are significant differences between the two positions. Cartesianism believes that the mind/soul is what gives humans the ability to possess consciousness and rationality. Nonhuman animals are thought to be alive, but irrational and nonconscious. This, of course, is why neo-Cartesianism is concerned mainly with determining to what degree nonhuman animals possess phenomenal consciousness. Thomism holds that the soul is the principle of life in biological organisms and is that which distinguishes life from nonlife. There are different types of souls (vegetative, sensitive, and rational), and they possess different types of abilities (reproduction, movement, and rationality, respectively).

For Cartesianism, testing for rationality in nonhuman animals is only one way for trying to determine if they are conscious. If they possess rationality, then they necessarily possess a mind/soul and are conscious. So, neo-Cartesianism is mainly concerned with whether animals have any degree of phenomenal consciousness, not necessarily whether they exhibit human levels of rationality. For Thomism, testing for rationality and self-consciousness is the main ways to determine if animals are persons capable of moral agency. This is because, according to Aquinas, consciousness is necessary to explain many animal behaviors:

For the type of every act or operation is determined by an object. Every operation of the soul is the act of a potentiality-either active

19 Thomas Aquinas, Summa theologiae [ST] II-II, q. 25, a. 3. All quotes from the ST are from Thomas Aquinas, Summa Theologica, trans. Fathers of the English Dominican Province (New York: Benziger Brothers, 1947).

20 Regardless of the debate regarding Descartes's position on animals, for sake of ease, I will use the terms "Cartesian position" and "Cartesianism" to refer to the view often attributed to Descartes entailing that animals lack phenomenal consciousness because they lack immaterial minds/souls. 
or passive. Now the objects of passive potentialities stand to these as the causal agents which bring each potentiality into its proper activity; and it is thus that visible objects, and indeed all sensible things, are related to sight and to the other senses. ${ }^{21}$

Here he is mentioning that objects in nature act on the passive senses of organisms. If an organism reacts to sights, sounds, smells, and so on, it is inferred that such an organism possesses the sense or senses that explain such behavior. Aquinas was not concerned with "what it is like" to be an organism, but only whether an organism possesses the ability to sense its environment. John Haldane helps to explain this further:

There is an old Aristotelian principle according to which acts are distinguished by their respective objects, powers are known by their acts, and substances are defined by their powers. ... What is of prime importance in determining if an individual is sensate is not the question of what it is like to be it, or even whether that Nagelian question arises; but rather the issue of how the individual is related to its environment. We do not need telepathy in order to attribute sensory awareness, for perception shows itself in the eye of the perceiver-vultus est index animi. On this basis there can be no serious doubt that dogs see other dogs. ${ }^{22}$

So, as Haldane suggests, Thomism does not entail a skepticism toward animal consciousness, while neo-Cartesianism does. If an organism reacts to its environment, it is assumed that the organism is conscious of that to which it reacts.

\section{Aquinas on Reasoning and Self-Knowledge}

In Thomism, rationality and self-awareness are the main criteria for moral agency and personhood for two major reasons. One is that the intellect and will are thought to be immaterial, making it possible for rational animals to possess free will. The other is that Aquinas's theory of self-knowledge entails that animals without intellects cannot be self-aware. To better understand these concepts, it will be good to discuss them further and

21 Thomas Aquinas, In II de anima, lec. 6, no. 305, found in Aristotle's De Anima, in the version of William of Moerbeke and the Commentary of St. Thomas Aquinas, trans. Kenelm Foster and Sylvester Humphries (New Haven, CT: Yale University Press, 1951).

22 John Haldane, Reasonable Faith (New York: Routledge, 2010), 122-23. 
draw out their implications for personhood.

\section{Reasoning}

The Aristotelian/Thomistic concept of reasoning sometimes gets confused in the contemporary discussion regarding animal minds. Indeed, the term "rational" can mean many different things, depending on the discipline of the person using it. For example, Alex Kacelnik has emphasized that there are at least three different meanings of "rational" used across the disciplines of philosophy, psychology, economics, and biology. ${ }^{23}$ Thus, it is crucial to be clear on the meaning of this term as understood in Thomism.

Following the Islamic philosopher Avicenna, Aquinas believes that nonhuman animals possess an "estimative power" that allows them to recognize intentions that are not directly perceived by their senses. ${ }^{24}$ The estimative power is similar to animal survival instincts and, among other things, recognizes whether something is useful or harmful to the animal perceiving. ${ }^{25}$ This power involves nonhuman animals processing and reacting to sense data they perceive and resembles empirical induction.

While nonhuman animals only appear to use logical reasoning (as they really use their estimative power), rational animals (humans) are able to reason because they possess immaterial intellects. For example, in a simple syllogism, there are both universal and particular concepts involved. The intellect is necessary to know and understand the universal statement that "all men are mortal." The senses are necessary to observe the particular statement that "Socrates is a man." The intellect concludes that "Socrates is mortal" based on the relation between the particular Socrates (who is judged to be a man) and the universal concept of humanity (which is known to always include mortality). Without the intellect, it would be impossible to know universal concepts, because universal concepts are immaterial. ${ }^{26}$ When universal concepts (forms) are conjoined with matter, they become particular instances of themselves. But observing a particular human will never give full knowledge of humanity. It is only when the universal and immaterial concept of humanity is abstracted from a particular human and stored in the immaterial intellect that knowledge of humanity is possible.

Thus, Aquinas believes that nonhuman animals are not capable of

23 Alex Kacelnik, "Meanings of Rationality," in Rational Animals? ed. Susan Hurley and Matthew Nudds (New York: Oxford University Press, 2006), 87-106.

24 ST I, q. 78, a. 4; Aquinas, Quaestiones disputatae de anima [Q.D. de anima], a. 13.

25 Eleonore Stump, Aquinas (New York: Routledge, 2003), 258.

26 See $S T$ I, q. 75 , a. 5 , and De veritate, q. 10, a. 8. 
complex abstract reasoning. Nonhuman animals are completely physical and do not possess immaterial intellects. ${ }^{27}$ Thus, they are unable to "know" universal forms and make judgments based on these forms and their relations. All they are able to do is observe particulars and react to their observations through their estimative powers. ${ }^{28}$

\section{Self-Knowledge}

Besides reasoning, Aquinas believes that the immaterial intellect makes it possible for rational animals to possess self-knowledge. The intellect makes this possible in two distinct ways: the self can be known through philosophical argumentation and also through the act of understanding. ${ }^{29}$ The latter way is the most important for the current discussion.

The intellect, according to Aquinas, is composed of two distinct powers: the passive intellect and the active intellect. ${ }^{30}$ Aquinas believes that, when the active intellect abstracts a form and deposits it into the passive intellect, the knower not only knows the form but also knows that they are knowing. ${ }^{31}$ So, in the act of knowing, the mind perceives itself. This is intuitive self-knowledge, since it is gained through direct cognition, as opposed to the discursive reasoning involved in philosophical argumentation. ${ }^{32}$

Aquinas says that, in the act of knowing, the intellect judges that there is an "I" that is distinct from the object that is known. ${ }^{33}$ This is because, as it gains knowledge, the intellect not only knows but also knows that it knows. The knower cognizes objects as objects that are known by a knower, an "I," and this creates an intuitive subject-object relation between knower and thing known. ${ }^{34}$

When the " $\mathrm{I}$ " is perceived in the act of knowing, the intellect judges that the "I" exists. ${ }^{35}$ Aquinas believes that, when the intellect cognizes

27 SCG II, ch. 82.

28 This would not qualify as rationality for Aquinas, but it is similar to the understanding of "rationality" in biology, which understands it as performing actions that are conducive to fitness. See Kacelnik, "Meanings of Rationality," 87-106.

29 Therese Scarpelli Cory, Aquinas on Human Self-Knowledge (New York: Cambridge University Press, 2014), 63-64. See ST I, q. 87, a. 1, and De veritate, q. 10, a. 8.

$30 \quad S T$ I, q. 79, aa. 2-3; Q.D. de anima, a. 4.

$31 \quad S T$ I, q. 87, a. 3; q. 93, a. 7, ad 4; SCG III, ch. 46.

32 For an in-depth treatment of this process of intuitive self-awareness see Cory, Aquinas on Human Self-Knowledge, 69-133.

33 Cory, Aquinas on Human Self-Knowledge, 84.

34 Cory, Aquinas on Human Self-Knowledge, 204.

35 Cory, Aquinas on Human Self-Knowledge, 84. 
something, it judges that the thing exists. ${ }^{36}$ Thus, if the intellect cognizes an "I" in the process of knowing, it also judges that the "I" exists. ${ }^{37}$ Over time, this awareness of an "I" produces a diachronic unity of consciousness in that it is known that the same "I" remains throughout all experiences. ${ }^{38}$

Nonhuman animals are thought to lack self-awareness because they are unable to perform acts of the mind such as simple apprehension and reasoning. They can sense and remember things, but this happens only on the level of particulars. Their lack of an immaterial intellect renders them incapable of storing universal concepts. Accordingly, they do not experience the act of knowing like rational animals do.

\section{Contemporary Theories Regarding Rationality and Self-Consciousness}

Now that Aquinas's position has been discussed, it will be good to review contemporary research regarding nonhuman animal minds. Since Thomism doubts the existence of abstract reasoning and self-awareness in nonhuman animals, I will discuss only contemporary research regarding these concepts. So, in what follows, I will focus on contemporary findings regarding animal rationality, metacognition, and episodic memory.

\section{Abstract Reasoning}

As mentioned, research into nonhuman animal rationality can be confusing because of the many different uses of the term "rationality." However, there has been plenty of contemporary research conducted on the specific type of abstract reasoning that Thomism entails. The literature on nonhuman animal rationality is massive, and space precludes a proper review. Thus, I will emphasize only the most relevant theories and their objections.

There are many researchers who believe there is evidence suggesting that some animals are capable of various types of logical inferences, including exclusionary inferences (great apes and $\operatorname{dog} s^{39}$ ), transitive inferences (monkeys, baboons, and sea lions ${ }^{40}$ ), and causal inferences (apes, monkeys,

\footnotetext{
De veritate, q. 10, a. 8.

Cory, Aquinas on Human Self-Knowledge, 84.

Cory, Aquinas on Human Self-Knowledge, 207.

For examples, see: Josep Call, "Descartes' Two Errors: Reason and Reflection in the Great Apes," in Hurley and Nudds, Rational Animals? 219-34; Call, "Inferences by Exclusion in the Great Apes: The Effect of Age and Species," Animal Cognition 9 (2006): 393-403; and Ágnes Erdőhegyi, József Topál, Zsófia Virányi, and Ádám Miklósi, "Dog-Logic: Inferential Reasoning in a Two-Way Choice Task and Its Restricted Use," Animal Behaviour 74 (2007): 725-37.

40 For examples, see: Brendan O. McGonigle and Margaret Chalmers, "Are Monkeys Logical?” Nature 267 (1977): 694-96; McGonigle and Chalmers, "Monkeys
} 
and rats $\left.{ }^{41}\right) \cdot{ }^{42}$ For example, in an experiment involving several different breeds, researchers tested for the existence of the ability for exclusionary inference in dogs. ${ }^{43}$ The tests involved a ball and two containers. In the tests, an experimenter would call the dog, show the dog a ball, and place the ball under one of the identical containers in a way so that the dog could not see the location of the ball. Afterward, the experimenter would provide the dog with information regarding the location of the ball by either lifting both containers, the empty container, or the container with the ball. The dog was then allowed to attempt to find the ball for a reward. A second version of the tests involved the lifting of the containers by strings without an experimenter present. The tests revealed that the dogs performed significantly higher than chance results and led the researchers to conclude that dogs are able to perform exclusionary inferences. ${ }^{44}$

However, there is no consensus on the issue of abstract rationality in animals, as its existence is doubted by other researchers. ${ }^{45}$ For example,

Are Rational!" The Quarterly Journal of Experimental Psychology 45B (1992): 198-228; Ronald J. Schusterman, Colleen Reichmuth Kastak, and David Kastak, "The Cognitive Sea Lion: Meaning and Memory in the Laboratory and in Nature," in The Cognitive Animal: Empirical and Theoretical Perspectives on Animal Cognition, ed. Marc Bekoff, Colin Allen, and Gordon M. Burghardt (Cambridge, MA: MIT Press, 2002), 217-28; and Robert M. Seyfarth and Dorothy L. Cheney, "The Structure of Social Knowledge in Monkeys," in Bekoff, Allan, and Burghardt, The Cognitive Animal, 379-84.

41 For examples, see: Anthony Dickinson and David Shanks, "Instrumental Action and Causal Representation," in Causal Cognition: A Multidisciplinary Debate, ed. Dan Sperber, David Premack, and Ann James Premack (Oxford: Clarendon, 1995), 5-25; Call, "Descartes' Two Errors," 219, 234; Aaron P. Blaisdell, Kosuke Sawa, Kenneth J. Leising, and Michael R. Waldmann, "Causal Reasoning in Rats," Science 311 (2006): 1020-22; and Marc D. Hauser and Laurie R. Santos, "The Evolutionary Ancestry of Our Knowledge of Tools: From Percepts to Concepts," in Creations of the Mind: Theories of Artifacts and Their Representation, ed. Eric Margolis and Stephen Laurence (New York: Oxford University Press, 2007), 267-88.

42 Jacob Beck, "Do Animals Engage in Conceptual Thought?" Philosophy Compass 7 (2012): 225-26.

43 Erdőhegyi, Topál, Virányi, and Miklósi, "Dog-Logic," 725-37.

44 Erdőhegyi, Topál, Virányi, and Miklósi, “Dog-Logic," 734-35.

45 For examples, see: José Luis Bermúdez, Thinking Without Words (New York: Oxford University Press, 2003), 109-32; Derek C. Penn and Daniel J. Povinelli, "Causal Cognition in Human and Nonhuman Animals: A Comparative, Critical Review," Annual Review of Psychology 58 (2007): 97-118; and Derek C. Penn, Keith J. Holyoak, and Daniel J. Povinelli, "Darwin's Mistake: Explaining the Discontinuity Between Human and Nonhuman Minds," Behavioral and Brain 
José Bermúdez argues that it is possible that animals are not using the same kind of abstract logic as humans use, but are instead using a type of proto-logic. ${ }^{46}$ Bermúdez believes that nonhuman animals are unable to perform abstract reasoning without language. Since nonhuman animals can think only nonlinguistically, they are unable to make truth judgments regarding their thoughts, since they lack the means to label their thoughts as true or false.

This would entail that the dogs were not performing an exclusionary inference such as:

1. Either the ball is in container A or the ball is in container B.

2. It is not true that the ball is in container $A$.

3. Therefore, it is true that the ball is in container B.

Instead, they would perform a proto-logical process similar to:

1. The ball is absent from container A.

2. The ball is in container $B$.

Without the ability to form thoughts about thoughts, such as "either A or B," the dogs would be unable to formulate the proposition that establishes a disjunctive syllogism. Furthermore, even if they were able to establish the first proposition, they would be unable to formulate a truth-conditional thought such as "it is not true that A" so as to guarantee the truth of the conclusion. Instead, utilizing a type of proto-logic, the dogs would be able to quickly learn to associate two subcontraries: "The ball is absent from container A" is associated with "The ball is in container B."

Thus, it could appear that the dogs use exclusionary inferences, when in fact they are simply associating subcontraries. They may not consider abstract logical relations, but merely perform the action that usually leads to a reward upon observing the absence of the ball in one of two containers. Their actions appear logical, but the process that determines their actions is not based on logic and does not produce necessarily valid conclusions.

Regarding the other types of reasoning, researchers have proposed ways in which it is possible that animals appear to use abstract reasoning but do not. ${ }^{47}$ For example, in addition to Bermúdez’s proposal, Michael Rescorla

Sciences 31 (2008): 109-30.

46 José Luis Bermúdez, "Animal Reasoning and Proto-Logic," in Hurley and Nudds, Rational Animals? 127-38.

47 Beck, "Do Animals Engage in Conceptual Thought?" 226. 
suggests it is possible that the appearance of exclusionary inferences can be explained by a process of Bayesian updating (named for Thomas Bayes) over cognitive maps. ${ }^{48}$ Associative learning and/or innate biases are also thought to provide an explanation for the appearance of transitive and causal inferences. ${ }^{49}$

Alongside this debate, there is a major position in the field of psychology called "dual-system theory" that is pertinent to the current discussion. Dual-system theorists hold that there are two distinct reasoning systems involved in human cognition. ${ }^{50}$ System 1 involves associative and intuitive processes, while system 2 involves rule-based and analytical processes. System-1 processes are thought to be automatic and non-conscious, while system-2 processes are thought to be controlled and conscious. ${ }^{51}$ Table 1 illustrates the two types of systems involved in dual-systems theory.

48 Michael Rescorla, "Cognitive Maps and the Language of Thought," The British Journal for the Philosophy of Science 60 (2009): 377-407.

49 See: Thomas R. Zentall, "The Case for a Cognitive Approach to Animal Learning and Behavior," Behavioural Processes 54 (2001): 65-78; C. De Lillo, D. Floreano, and F. Antinucci, "Transitive Choices by a Simple, Fully Connected, Backpropagation Neural Network: Implications for the Comparative Study of Transitive Inference," Animal Cognition 4 (2001): 61-68; Collin Allen, “Transitive Inference in Animals: Reasoning or Conditioned Associations?" in Hurley and Nudds, Rational Animals? 175-86; and Penn and Povinelli, "Causal Cognition."

50 For a somewhat recent explanation and review of dual-system theories, see Keith Frankish, "Dual-Process and Dual-System Theories of Reasoning," Philosophy Compass 5 (2010): 914-26.

51 Frankish, "Dual-Process and Dual-System Theories," 914. 
Table 1: Features Attributed to Aspects of the Dual-Systems

\begin{tabular}{|l|l|l|}
\hline & \multicolumn{1}{|c|}{ System 1 } & \multicolumn{1}{|c|}{ System 2 } \\
\hline Process & Automatic & Controlled \\
\hline & Nonconscious or preconscious & Conscious \\
\hline & Heuristic & Analytic \\
\hline & Associative & Rule-based \\
\hline Content & Actual & Hypothetical \\
\hline & Concrete & Abstract \\
\hline & Contextualized & Decontextualized \\
\hline Evolution & Evolutionarily old & Evolutionarily recent \\
\hline & Shared with animals & Unique to humans \\
\hline & Nonverbal & Language-involving \\
\hline & $\begin{array}{l}\text { Serves genetic goals ("short- } \\
\text { leash" control) }\end{array}$ & $\begin{array}{l}\text { Serves individual goals (“long- } \\
\text { leash" control) }\end{array}$ \\
\hline
\end{tabular}

Source: Condensed from Frankish, "Dual-Process an Dual-System Theories of Reasoning" (see note 50), 992.

Dual-process and dual-system theories have been prominent in the field of psychology for decades, starting in the late $1970 s .^{52}$ Researchers argue for these theories mainly based on findings from studies performed on human reasoning processes. ${ }^{53}$ But there are dual-system theorists who believe that processes in system 2 are evolutionarily late and uniquely human. ${ }^{54}$ For example, Jonathan Evans explains:

52 Frankish, "Dual-Process and Dual-System Theories," 916; Jonathan St. B. T. Evans and Keith E. Stanovich, "Dual-Process Theories of Higher Cognition: Advancing the Debate," Perspectives on Psychological Science 8, no. 3 (2013): 223-41, at 223.

53 See: Seymour Epstein, "Integration of the Cognitive and the Psychodynamic Unconscious," American Psychologist 49 (1994): 709-24; Eliot R. Smith and Jamie DeCoster, "Dual-Process Models in Social and Cognitive Psychology: Conceptual Integration and Links to Underlying Memory Systems," Personality and Social Psychology Review 4 (2000): 108-31; Arie W. Kruglanski and Edward Orehek, "Partitioning the Domain of Social Inference: Dual Mode and Systems Models and Their Alternatives," Annual Review of Psychology 58 (2007): 291-316; and Frankish, "Dual-Process and Dual-System Theories."

54 For examples, see: Jonathan St. B. T. Evans and David E. Over, Rationality and Reasoning (Hove, UK: Psychology Press, 1996); Jonathan St. B. T. Evans, Thinking Twice: Two Minds in One Brain (New York: Oxford University Press, 2010); and Keith E. Stanovich, Rationality and the Reflective Mind (New York: Oxford University Press, 2011). 
It is evident that humans resemble other animals in some respects but are very different in others. Quite obviously, no other animal can engage in the forms of abstract hypothetical thought that underlie science, engineering, literature, and many other human activities. More basically, we propose that other animals are much more limited in their metarepresentational and simulation abilities, thus leading to limitations (compared with humans) in their ability to carry out forms of behavior that depend on prior appraisal of possible consequences. Thus, a key defining feature of Type 2 processing - the feature that makes humans unique-is cognitive decoupling: the ability to distinguish supposition from belief and to aid rational choices by running thought experiments. ${ }^{55}$

There are many critics of dual-system theories, despite their major influence in psychology. Opponents have argued that dual-system theories are often formulated using vague terms, contain unreliably aligned attributes (i.e., supposed attributes of systems 1 and 2 are not consistently observed together), view different processes as types when they should view them as styles, and are supported by ambiguous or unconvincing evidence. ${ }^{56}$ These critics often suggest that the evidence put forward for dual-system theories can just as easily support single-process theories. ${ }^{57}$

However, Evans and Keith Stanovich emphasize that these critics often overgeneralize and make attacks that are aimed at all dual-system theories but do not apply to many of the nuanced dual-system positions. ${ }^{58}$ They argue that there is plenty of evidence to be found that supports a carefully

55 Evans and Stanovich, "Dual-Process Theories of Higher Cognition," 236.

56 Evans and Stanovich, "Dual-Process Theories of Higher Cognition," 227.

57 For examples, see: Arie W. Kruglanski, Woo Young Chun, Hans Peter Erb, Antonio Pierro, Lucia Mannetti, and Scott Spiegel, "A Parametric Unimodel of Human Judgment: Integrating Dual-Process Frameworks in Social Cognition from a Single-Mode Perspective," in Social Judgments: Implicit and Explicit Processes, ed. Joseph P. Forgas, Kipling D. Williams, and William von Hippel (New York: Cambridge University Press, 2003), 137-61; Magda Osman, "An Evaluation of Dual-Process Theories of Reasoning," Psychonomic Bulletin and Review 11 (2004): 988-1010; Gideon Keren and Yaacov Schul, "Two Is Not Always Better Than One: A Critical Evaluation of Two-System Theories," Perspectives on Psychological Science 4 (2009): 533-50; Arie W. Kruglanski and Gerd Gigerenzer, "Intuitive and Deliberate Judgments Are Based on Common Principles," Psychological Review 118 (2011): 97-109; and Peter Carruthers, "Animal Minds Are Real, (Distinctively) Human Minds Are Not," American Philosophical Quarterly 50 (2013): 233-48.

58 Evans and Stanovich, "Dual-Process Theories of Higher Cognition," 223-35. 
defined dual-process theory: "The evidence [for dual-process theories] is compelling and ... a very clear theoretical basis for the two-process distinction has now emerged. Such theories can account for a wide range of phenomena in the reasoning, judgment, and decision-making literatures that have been the subject of several recent books." ${ }^{\text {99 }}$

Although the debate continues regarding whether animals are capable of abstract reasoning, there is plenty of evidence to support the conclusion that animals most likely are not capable of such reasoning. Although it might appear that they are able to perform what could be labeled as logical reasoning, there is often an explanation for their behavior that does not necessitate invoking abstract logic. At a minimum, it is reasonable to conclude that nonhuman animals do not act rationally, but rather are guided by system-1 processes.

\section{Self-Awareness}

There are several theories regarding which attributes would provide evidence of self-awareness if found in nonhuman animals. The most widely researched include whether nonhuman animals possess mind-reading capabilities (i.e., theory of mind), mirror self-recognition, metacognition, and episodic memory. ${ }^{60}$ In what follows, due to space constraints, I will mainly discuss the debates regarding nonhuman animal metacognition and episodic memory. ${ }^{61}$

\section{Metacognition}

An area of research that is extremely pertinent to this essay is the scientific and philosophical study of human and nonhuman metacognition. As with rationality, there is more than one understanding of "metacognition" in

59 Evans and Stanovich, "Dual-Process Theories of Higher Cognition," 237.

60 For a good discussion of contemporary research into animal self-consciousness, see Kristin Andrews, The Animal Mind: An Introduction to the Philosophy of Animal Cognition (New York: Routledge, 2015), 70-77.

61 I will not discuss mirror self-recognition because I do not think it provides compelling evidence for self-awareness. Skeptical researchers have argued that nonhuman animals might simply recognize their own bodies, not their own selves (e.g., Cecilia M. Heyes, "Reflections on Self-Recognition in Primates," Animal Behaviour 47 [1994]: 909-19, esp. 915), or recognize that their body and the body in the mirror are similar (for example, see Thomas Suddendorf and David L. Butler, "The Nature of Visual Self-Recognition," Trends in Cognitive Sciences 17 [2013]: 121-27). Similarly, as will be shown below, it seems that self-recognition can be explained through anoetic awareness instead of autonoetic awareness. Also, I will not discuss nonhuman animal mind-reading for space reasons and because metacognition and episodic memory are more pertinent to Aquinas's concepts. 
the literature. Metacognition is often narrowly defined as "thinking about one's own thoughts." More broadly, Joëlle Proust defines it as "the kinds of processes involved, and the self-knowledge gained, in thinking about, and in controlling, one's own thinking." 62

However, it is highly debated as to what qualifies as metacognition. Some researchers believe that metacognition necessarily involves representing one's own mental state as a mental state. ${ }^{63}$ This is known as the "self-attributive" view. A self-attributive thought would be a self-referential second-order representation of a first-order representation (e.g., "I believe that I know/perceive/believe/feel/etc. that it is raining"). ${ }^{64}$ Other researchers believe that metacognition merely requires controlling and monitoring one's own cognitive processes. ${ }^{65}$ This is thought to possibly involve nonconceptual, representational processes and is known as the "self-evaluative" view.

The main debate regarding nonhuman animals and metacognition is not whether they are capable of self-attributive metacognition, but whether they are capable of self-evaluative metacognition. Accordingly, many researchers argue that nonhuman animals are capable of self-evaluative metacognition. ${ }^{66}$ For example, in one study conducted by Kazuo Fujita, two tufted capuchin monkeys were tested for the ability to recognize their own memories. ${ }^{67}$ In the study, they were presented with a sample

62 Joëlle Proust, "Metacognition," Philosophy Compass 5, no. 11 (November 2010): 989-98, at 989.

63 Proust, "Metacognition," 989.

64 Santiago Arango-Muñoz, "Two Levels of Metacognition," Philosophia 39, no. 1 (2011): 71-82, at 73 .

65 Proust, "Metacognition," 989.

66 For examples, see: Wendy E. Shields, J. David Smith, and David A. Washburn, "Uncertain Responses by Humans and Rhesus Monkeys (Macaca mulatta) in a Psychophysical Same-Different Task," Journal of Experimental Psychology: General 126 (1997): 147-64; Robert R. Hampton, "Rhesus Monkeys Know When They Remember," Proceedings of the National Academy of Sciences of the United States of America 98 (2001): 5359-62; David A. Washburn, J. David Smith, and Wendy E. Shields, "Rhesus Monkeys (Macaca mulatta) Immediately Generalize the Uncertain Response," Journal of Experimental Psychology: Animal Behavior Processes 32 (2006): 185-89; J. David Smith, Michael J. Beran, Joshua S. Redford, and David A. Washburn, "Dissociating Uncertainty Responses and Reinforcement Signals in the Comparative Study of Uncertainty Monitoring," Journal of Experimental Psychology: General 135 (2006): 282-97; and Nate Kornell, Lisa K. Son, and Herbert S. Terrace, "Transfer of Metacognitive Skill and Hint Seeking in Monkeys," Psychological Science 18 (2007): 64-71.

67 Kazuo Fujita, "Metamemory in Tufted Capuchin Monkeys (Cebus apella)," Animal Cognition 12 (2009): 575-85. 
shape on a computer screen. After a delayed period of time, they were given the choice to bring up a screen that would present them with nine shapes (one of which matched the initial shape) or bring up a screen that had an escape button. If they chose the matching task and then correctly chose the matching shape, they were rewarded with food 100 percent of the time. If they chose the wrong shape, they received nothing and a buzzer sounded for half a second. If they chose the escape screen, they were rewarded with food 50-75 percent of the time. One of the monkeys was found to reliably opt out of the matching task when there was a significant enough delay between the initial shape and the choice screen. If the delay between the screens was short enough, the same monkey regularly chose the matching task and its accompanied guaranteed reward for a correct answer. This suggests that capuchins are capable of monitoring and/or recognizing their own memory traces. ${ }^{6}{ }^{6}$ However, Fujita noted that the capuchins seemed to have access only to the strength of their memories and not the contents. So, although they seemed to possess metacognitive abilities regarding their memories, these were limited.

Other researchers believe that apparently self-evaluative behaviors in nonhuman animals are explainable through associative processes alone, without metacognition. ${ }^{69}$ For example, David Smith notes that it is possible that the rewards coinciding with the escape option in experiments like Fujita's become more attractive as the monkeys associate them with an easier reward..$^{70}$ Likewise, Mike Le Pelley argues that the behavior of the monkeys can be explained as learning to associate harder trials with unpleasant stimuli, such as the buzzer sound. ${ }^{71}$ Thus, instead of monitoring the strength of their own memories, it is possible that the monkeys are simply learning to associate longer waiting periods with unpleasant buzzer noises.

68 Fujita, "Metamemory," 583-84.

69 For examples, see: Peter Carruthers, "Meta-Cognition in Animals: A Skeptical Look," Mind and Language 23 (2008): 58-89; Robert R. Hampton, "Multiple Demonstrations of Metacognition in Nonhumans: Converging Evidence or Multiple Mechanisms?" Comparative Cognition and Behavior Reviews 4 (2009): 17-28; J. Jozefowiez, J. E. R. Staddon, and D. T. Cerutti, "Metacognition in Animals: How Do We Know that They Know?" Comparative Cognition and Behavior Reviews 4 (2009): 29-39; M. E. Le Pelley, "Metacognitive Monkeys or Associative Animals? Simple Reinforcement Learning Explains Uncertainty in Nonhuman Animals," Journal of Experimental Psychology: Learning, Memory, and Cognition 38 (2012): 686-708.

70 J. David Smith, "The Study of Animal Metacognition," Trends in Cognitive Sciences 13 (2009): 389-96, at 390.

71 Le Pelley, "Metacognitive Monkeys or Associative Animals?" 686. 
Regardless, there are many researchers who believe that nonhuman animals lack the physiological capacity for metacognition. ${ }^{72}$ Indeed, the evidence has led some to formulate bold hypotheses in regard to human uniqueness. For example, philosopher Derek Penn, psychologist Keith Holyoak, and psychologist Daniel Povinelli have proposed what they call the "relational reinterpretation hypothesis." 73 The hypothesis entails that "the discontinuity between human and nonhuman minds extends ... to any cognitive capability that requires reinterpreting perceptual relations in terms of higher-order, structural, role-governed relations." ${ }^{34}$ In particular the hypothesis suggests that:

Animals of many taxa employ functionally compositional, particular-involving, syntactically structured mental representations about observable features, entities, and relations in the world around them. Furthermore, they form abstract representations about statistical regularities they perceive in the behavior of certain classes of physical objects (e.g., observable causal relations) and other animate agents (e.g., affiliative interactions) and are capable of using these representations off-line to make decisions in a flexible, reliable, and ecologically rational (i.e., adaptive) fashion. Human animals alone, however, possess the additional capability of reinterpreting these perceptually grounded representations in terms of higher-order, role-governed, inferentially systematic, explicitly structural relations-or, to be more precise, of approximating these higher-order features of a PSS [physical symbol system], subject to the evolved, content-specific biases and processing capacity limitations of the human brain. ${ }^{75}$

Santiago Arango-Muñoz believes that, in addition to the hypothesis

72 For examples, see: Daniel J. Povinelli and Jennifer Vonk, "Chimpanzee Minds: Suspiciously Human?" Trends in Cognitive Sciences 7 (2003): 157-60; Povinelli and Vonk, "We Don't Need a Microscope to Explore the Chimpanzee's Mind," in Hurley and Nudds, Rational Animals? 385-412; Carruthers, "Meta-Cognition in Animals," 58-89; Joseph Call and Michael Tomasello, "Does the Chimpanzee Have a Theory of Mind? 30 Years Later," Trends in Cognitive Science 12 (2008): 187-92; and José Luis Bermúdez, "Mindreading in the Animal Kingdom," in The Philosophy of Animal Minds, ed. Robert W. Lurz (New York: Cambridge University Press, 2009), 145-64.

73 Penn, Holyoak, and Povinelli, “Darwin's Mistake," 127-29.

74 Penn, Holyoak, and Povinelli, "Darwin's Mistake," 127.

75 Penn, Holyoak, and Povinelli, "Darwin's Mistake," 127. 
of Penn, Holyoak, and Povinelli, the evidence supports a two-level view of metacognition that is compatible with dual-process theories. ${ }^{76} \mathrm{He}$ believes the self-attributive-self-evaluative debate is the result of both sides arguing that only one view is correct, when both views are correct in that each describes a distinct level of metacognition. Similarly to dual-process theories, Arango-Muñoz proposes that the self-attributive view is describing a high-level (system 2) form of metacognition in which subjects use concepts and theories to interpret their behavior. ${ }^{77}$ The self-evaluative view describes a low-level (system 1) form of metacognition in which feelings guide their subjects to adjust cognitive activities without engaging in second-order thought. ${ }^{78} \mathrm{He}$ believes that nonhuman animals are capable of only low-level metacognition, while humans are capable of both low- and high-level metacognition.

Similarly, Janet Metcalfe and Lisa Son believe the evidence suggests a distinction between anoetic, noetic, and autonoetic metacognition. ${ }^{79}$ Anoetic metacognition involves judgments that are stimulus-bound, spatially and temporally bound to the current time.$^{80}$ In other words, it is an animal making judgments about what it is currently experiencing. Noetic metacognition involves making judgments about representations of objects and events that are not physically present. ${ }^{81}$ Finally, autonoetic metacognition involves self-referential judgments (similar to self-attributive metacognition). Metcalfe and Son discuss there not being sufficient evidence to conclude nonhuman animals are capable of autonoetic metacognition and the fact that it is even debated whether nonhuman animals possess anoetic and noetic metacognitive abilities.

The existence of hypotheses such as these indicates the amount and compelling nature of the evidence against higher forms of nonhuman animal metacognition. Also, it is striking that some researchers believe the evidence points to dual types of metacognition in humans and nonhuman animals. This adds to the strength of dual-process theories regarding rationality. As it stands, nonhuman animals are not viewed as serious candidates for self-attributive or autonoetic metacognition.

76 Arango-Muñoz, “Two Levels of Metacognition,” 71-82.

77 Arango-Muñoz, “Two Levels of Metacognition,” 77.

78 Arango-Muñoz, "Two Levels of Metacognition.”

79 Janet Metcalfe and Lisa K. Son, "Anoetic, Noetic, and Autonoetic Metacognition," in Foundations of Metacognition, ed. Michael J. Beran, Johannes L. Brandl, Josef Perner, and Joëlle Proust (New York: Oxford University Press, 2012), 289-301. 


\section{Episodic Memory}

Besides self-attributive metacognition, episodic memory is probably one of the most promising attributes that indicates self-awareness. Episodic memory is a type of memory in which the subject remembering an event remembers the event from the subject's perspective. This is distinguished from semantic memory, which is simply remembering facts about the world apart from personal experience. Episodic memory is associated with self-awareness for reasons already mentioned. When people remember that events have happened to them, they develop a diachronic unity of consciousness over time.

Many researchers have argued there is evidence of episodic (or episodic-like) memory in nonhuman animals. ${ }^{82}$ For example, one study involved testing for episodic memory in scrub jays, which are known for their food caching abilities. ${ }^{83}$ The scrub jays were allowed to cache differing types of food that were either perishable (mealworms and crickets) or nonperishable (peanuts). The study showed that, if the scrub jays were released before their preferred food became inedible, they would return to the locations of their preferred food. If they were released after their preferred food became inedible, they would return only to their nonpreferred food caches. These findings suggested that the scrub jays remembered at least the where, what, and when aspects of their food caching. ${ }^{84}$ This is evidence of episodic-like memory, and possibly episodic memory.

However, as with metacognition, some researchers believe it is possible to explain episodic-like behavior in simpler terms. ${ }^{85}$ For example, it is

82 For examples, see: Nicola S. Clayton and Anthony Dickinson, "Episodic-Like Memory During Cache Recovery by Scrub Jays," Nature 395 (1998): 272-74; Stephanie J. Babb and Jonathan D. Crystal, "Episodic-Like Memory in the Rat," Current Biology 16 (2006): 1317-21; Gema Martin-Ordas, Daniel Haun, Fernando Colmenares, and Joseph Call, "Keeping Track of Time: Evidence for Episodic-Like Memory in Great Apes," Animal Cognition 13 (2010): 331-40; Miranda C. Feeney, William A. Roberts, and David F. Sherry, "Mechanisms of What-Where-When Memory in Black-Capped Chickadees (Poecile atricapillus): Do Chickadees Remember 'When'?" Journal of Comparative Psychology 125 (2011): 308-16; and Jonathan D. Crystal, Wesley T. Alford, Wenyi Zhou, and Andrea G. Hohmann, "Source Memory in the Rat," Current Biology 23 (2013): 387-91.

83 N. S. Clayton, D. P. Griffiths, N. J. Emery, and A. Dickinson, "Elements of Episodic-Like Memory in Animals," Philosophical Transactions of the Royal Society: London B 356 (2001): 1483-91.

84 Clayton, Griffiths, Emery, and Dickinson, "Elements of Episodic-Like Memory in Animals," 1490.

85 For examples, see: Howard Eichenbaum and Norbert Fortin, "Episodic Memory 
possible the scrub jays simply possess real-time semantic (nonpersonal) knowledge of the locations and ages of their food caches ${ }^{86}$ Recalling the possibilities involving the capuchins and their memories, it is possible that the scrub jays learned to associate longer time intervals with rotten food. Thus, they could simply return to food caches of which they possess stronger memories or perishable-food caches only when shorter intervals have lapsed. ${ }^{87}$

One of the most interesting aspects of episodic memory, and also relevant to this essay, is that episodic memory has been found to coincide with the ability to mentally "time-travel." Mental time-travel is the ability to remember or to imagine oneself in the past or the future. Psychologists believe that the two coincide due in part to studies involving damage to the human brain.

For example, in 1981, a man known as K.C. was involved in a motorcycle accident in which he suffered brain damage. ${ }^{88} \mathrm{~K}$.C. exhibited a rare type of retrograde amnesia in which he cannot remember anything that happened to him from a personal perspective (episodic memory), although he retained knowledge of facts about the world and himself (semantic memory). For example, K.C. knew the address and appearance of the house in which he spent his first nine years of life, but he did not remember a single event that took place there. Moreover, K.C. had a similar problem regarding thinking about his future. Endel Tulving explains that:

K.C. cannot think about his own personal future. Thus, when asked, he cannot tell the questioner what he is going to do later on that day, or the day after, or at any time in the rest of his life, any more than he can say what he did the day before or what events have happened in his life. When he is asked to describe the state of his mind when he thinks about his future, whether the next 15 minutes

and the Hippocampus," Current Directions in Psychological Science 12 (2003): 53-57; Thomas Suddendorf and Janie Busby, "Mental Time Travel in Animals?" Trends in Cognitive Sciences 7 (2003): 391-96; and Robert R. Hampton and Bennett L. Schwartz, "Episodic Memory in Nonhumans: What, and Where, is When?" Current Opinion in Neurobiology 14 (2004): 192-97.

86 Hampton and Schwartz, "Episodic Memory in Nonhumans," 194.

87 Eichenbaum and Fortin, "Episodic Memory and the Hippocampus," 55.

88 See R. Shayna Rosenbaum, Stefan Köhler, Daniel L. Schacter, Morris Moscovitch, Robyn Westmacott, Sandra E. Black, Fuqiang Gao, and Endel Tulving, "The Case of K.C.: Contributions of a Memory-Impaired Person to Memory Theory," Neuropsychologia 43 (2005): 989-1021. 
or the next year, he again says that it is "blank." 99

Studies of K.C. have led researchers to conclude that episodic and semantic memory are based in different sets of neural mechanisms. ${ }^{90}$ Thus, if a human or nonhuman animal possesses semantic memory, this does not necessarily entail that they will possess episodic memory. Also, as mentioned, K.C.'s case has led to the conclusion that episodic memory is necessary for mental time-travel. This is striking because it entails that, if nonhuman animals do not possess the ability for episodic memory, then not only can they not remember the past from a personal perspective, but they also cannot think of or anticipate future personal events. As will be explained below, this has major implications for the problem of animal suffering and the status of nonhuman animals regarding moral agency.

Additionally, Tulving emphasizes that the capacity for episodic memory does not just enable personal mental time-travel; it also enables a present sense of self:

To describe autonoetic consciousness with regards to episodic memory, there is a natural bias to cast the discussion in terms of awareness of the past. Autonoetic consciousness is not limited to the past, however; it encompasses the capacity to represent the self's experiences in the past, present, and future. When one is autonoetically aware of one's experiences in the past, one recollects the past and, therefore, retrieves information from episodic memory. But also dependent on autonoetic consciousness and, we argue, closely related to episodic memory is the ability to be aware of the self's present. ${ }^{91}$

Thus, the absence of episodic memory in nonhuman animals suggests that they are not only unable to personally experience the past and future but also unable to personally experience the present.

As with rationality and metacognition, some researchers believe that episodic memory and the ability for personal mental time-travel are

89 Endel Tulving, "Episodic Memory and Autonoesis: Uniquely Human?" in The Missing Link in Cognition: Origins of Self-Reflective Consciousness, ed. Herbert S. Terrace and Janet Metcalfe (New York: Oxford University Press, 2005), 4-56, at 26.

90 Tulving, "Episodic Memory and Autonoesis," 24.

91 Mark A. Wheeler, Donald T. Stuss, and Endel Tulving, "Toward a Theory of Episodic Memory: The Frontal Lobes and Autonoetic Consciousness," Psychological Bulletin 121, no. 3 (1997): 331-54, 335. 
unique to humans. ${ }^{92}$ This is another area where the evidence points to dual processes in humans and nonhuman animals. Regarding memory, it seems that some nonhuman animals have episodic-like memory (knowing the impersonal where, what, and when of events), while humans uniquely possess both episodic-like and episodic memory. For example, Tulving explains that:

Many kinds of complex behaviors of many kinds of animals can be, and have been, interpreted as manifesting episodic memory, and in many cases these behaviors do have many features in common with behaviors that are grounded in episodic memory. Practically invariably, however, the same behaviors can also be interpreted more parsimoniously, as manifestations of semantic or declarative memory, which do not provide for, and do not require postulation of, the apprehension of subjective past or subjective future time. ${ }^{93}$

Thus, to date, it seems that most, if not all, nonhuman animals do not have the capability for self-awareness that is found in humans. For one, the evidence suggests that humans uniquely possess the ability for higher-order metacognition. Nonhuman animals are not able to think about their thoughts, and thus are unaware of themselves as the possessors of such thoughts. Additionally, episodic memory is believed to be unique to humans. This entails that nonhuman animals cannot remember the past as it happened to them personally or personally experience the present. This also means nonhuman animals are unable to anticipate or think about their personal futures.

\section{Implications of Neo-Thomism for the Problem of Animal Suffering}

So, the Thomistic view of nonhuman animals needs updating. It certainly is outdated to explain animal cognition and behavior solely through the broad term "estimative power." However, the crucial aspects of the Thomistic view of nonhuman animals are in no danger of replacement.

In light of the Thomistic view of nonhuman animal minds, it was

92 For examples, see: William A. Roberts, “Are Animals Stuck in Time?" Psychological Bulletin 128, no. 3 (2002): 473-89; Suddendorf and Busby, "Mental Time Travel in Animals?" 391-96; Tulving, "Episodic Memory and Autonoesis," 3-56; Thomas Suddendorf and Michael C. Corballis, "The Evolution of Foresight: What Is Mental Time Travel, and Is It Unique to Humans?" Behavioral and Brain Sciences 30 (2007): 299-313.

93 Tulving, "Episodic Memory and Autonoesis," 48. 
shown that there is no conclusive evidence that nonhuman animals possess either higher-order (system 2) rationality or higher-order abilities associated with self-awareness, such as self-attributive or autonoetic metacognition and episodic memory. Thus, nonhuman animals are not rational, do not have higher-order access to their mental states, and cannot remember or imagine themselves in the past, present, or future. This is similar to the neo-Cartesian option 3: "Some non-human creatures have states that have intrinsic phenomenal qualities analogous to those possessed by humans when they are in states of pain. These creatures lack, however, any higher-order states of being aware of themselves as being in first-order states."

Thus, the evidence suggests that there is no problem of animal suffering. If nonhuman animals are neither rational nor self-aware, then they are not suffering as persons. For one, nonhuman animals most likely lack higher-order access to their suffering regardless of whether it is experienced phenomenally or not. If nonhuman animals are incapable of higher-order thoughts regarding their lower-order experiences, this means that nonhuman animals are incapable of higher-order thoughts such as "I believe that I feel pain" or "I believe that I wish to avoid pain." As humans, we have higher-order access to our lower-order mental states throughout our entire lives. So it is hard to imagine what this would be like. However, the nonhuman animal's lack of self-attributive or autonoetic metacognition sheds light on the nonpersonal nature of their experiences. As Aquinas argues, nonhuman animals do not know that they know or make judgments in a self-referential manner. As hard as it is to imagine, there are experiences of pain and suffering in nonhuman animals but there are no personal thoughts/experiences/awarenesses of these experiences.

Also, nonhuman animals are most likely incapable of abstract rationality. This is relevant to the problem of animal suffering because nonlinguistic creatures could never form abstract concepts regarding their suffering. For instance, arational animals cannot reach the understanding that they ought not to be in a state of pain or suffering. Moreover, it is important to remember that their lack of rationality entails that they do not act for logical reasons. Thus, arational animals cannot be said to have any logical reasons for acting in ways that avoid future experiences of pain. Pain behaviors are simply explainable through associative learning and, at most, anoetic and noetic metacognition.

In addition to the Thomistic distinctives of metacognition and rationality, it was found that nonhuman animals most likely lack episodic memory, and thus any sense of a personal past, present, and future. So, if they experience pain and suffering, these are experienced only in a nonpersonal present. Nonhuman animals neither self-referentially remember suffering 
they have experienced, nor self-referentially experience current suffering, nor self-referentially anticipate future suffering they may encounter. This is evidence for Aquinas's notion that nonhuman animals lack a sense of self, diachronic or otherwise, because they are not aware of a personal process of abstracting and storing knowledge of universals. ${ }^{94}$

These considerations provide an answer to the problem of animal suffering not only as it relates to animal pain but also as it relates to any other type of suffering that animals might experience, such as fear and sorrow. If nonhuman animals are not self-aware, then they lack higher-order access to any of these unpleasant states. Thus, there is no person, qua person, that experiences pain or suffering in the nonhuman animal kingdom.

\section{An Objection to the Neo-Thomistic Solution}

A major objection at this point could be that the neo-Thomistic concept of arational and nonpersonal animals does not avoid the problem. For example, when arguing against neo-Cartesian option 3 (which was noted as being similar to the neo-Thomistic position), Robert Francescotti states:

It is not clear that position 3 is even coherent. We are to imagine that some other animals have mental states with "intrinsic phenomenal qualities analogous to those possessed by humans," but they are not aware of being in those states, and so, Murray explains, "there is simply no victim or subject for whom it can be said that there is a way it is like for it to be in such a state of pain" (Murray 2008, 56). However, if these states are phenomenally similar to those we have, as 3 claims, then there would be a "what it is like" character to these states, and in particular they would have something similar to the distressful feel of our pain states. So there would be a clear sense in which some other animals suffer. ${ }^{95}$

Regardless of whether animals are persons, if they are experiencing unpleasant mental and physical states, then the evils remain. This objec-

94 For further evidence along these lines, see Hans J. Markowitsch and Angelica Staniloiu, "Memory, Autonoetic Consciousness, and the Self," Consciousness and Cognition 20 (2011): 16-39. Markowitsch and Staniloiu argue that autonoetic consciousness and episodic memory are required for "episodic-autobiographical memory," or EAM (a diachronic sense of self), and that EAM is probably unique to humans.

95 Francescotti, “The Problem of Animal Pain and Suffering," 115-16 (citing Murray, Nature Red in Tooth and (law). 
tion, however, seems to be avoidable through noting important distinctions and reemphasizing the Thomistic concept of consciousness.

First, it will be helpful to discuss a distinction that has been emphasized by Tulving. Tulving and his associates make a careful distinction between consciousness and awareness. He says that "consciousness" is "a general capacity that an individual possesses for particular kinds of mental representations and subjective experiences." "A6 "Awareness" is "a particular manifestation or expression of this general capacity." ${ }^{\prime 7}$ Tulving explains that:

Consciousness, like other capacities of living systems, has no object; it is not directed at anything. It is like a stage that allows some actions, but not others, to take place on it, but it does not prescribe action. Awareness always has an object; it is always of something. Thus, awareness presumes consciousness, but consciousness does not imply awareness: Consciousness is a necessary but not sufficient condition of awareness. ${ }^{98}$

Accordingly, I have been careful throughout this essay to use the terms "consciousness" and "self-awareness" when referring to humans and nonhuman animals.

Regardless, Francescotti says that pain states having a "what it is like" character are "clear" cases of nonhuman animal suffering. But it is not clear that these are "clear" cases of suffering. This is because, as concluded above, it is likely that nonhuman animals are conscious of pain, but not that they are self-referentially aware of their pain. If nonhuman animals lack metacognitive abilities, then they can only be conscious of pain and suffering. Pain and suffering would be just one part of the kaleidoscope of their conscious experience. They would react to it according to their instincts and associatively learned behavior. If they possess lower-order metacognitive abilities, then they can be aware, yet not self-referentially aware, of pain and suffering. They would experience, focus upon, and make judgments regarding pain and suffering, yet they would not do this on a personal level.

Tulving's three levels of consciousness and awareness (anoetic, noetic, and autonoetic) are helpful here as well. Of anoetic consciousness, he explains: "[It] is temporally and spatially bound to the current situation. Organisms possessing only anoetic consciousness are conscious in the

96 Wheeler, Stuss, and Tulving, "Toward a Theory of Episodic Memory," 335.

97 Wheeler, Stuss, and Tulving, "Toward a Theory of Episodic Memory," 335.

98 Wheeler, Stuss, and Tulving, “Toward a Theory of Episodic Memory," 335. 
sense that they are capable of perceptually registering, internally representing, and behaviourally responding to aspects of the present environment, both external and internal." ${ }^{\text {"99 }}$ Concerning noetic consciousness, he further states in the same place: "[It] allows an organism to be aware of, and to cognitively operate on, objects and events, and relations among objects and events, in the absence of these objects and events. The organism can flexibly act upon such symbolic knowledge of the world." As explained, nonhuman animals possess anoetic consciousness and possibly noetic consciousness, but not autonoetic consciousness.

If neo-Cartesian option 3 is necessarily tied to the "intrinsic phenomenal qualities" of states possessed by nonhuman animals, then perhaps Francescotti's objection holds here. But as explained above, neo-Thomism does not necessarily focus on "what it is like" for animals to experience the world, but only that they are conscious. Thus, regardless of whether autonoetic consciousness is the only type of consciousness accompanied with qualia, noetic, or anoetic consciousness is all that is needed to meet the Thomistic standard for consciousness.

However, even if there is "something it is like" for animals to experience pain and suffering, this does not mean that the experience is necessarily intrinsically evil. Getting back to Francescotti's objection, as mentioned, it is not clear that the anoetic and noetic experiences of pain and suffering constitute suffering. This can be shown by emphasizing two Thomistic concepts.

\section{Evil as Privation Theory}

First, it is important to remember that Thomism entails what is known as the "evil as privation theory." Aquinas discusses evil in many places in his writings, but he probably defines it most clearly in his discussion in the Summa theologiae [ST]: "Evil is the absence of the good, which is natural and due to a thing." ${ }^{100}$ It is important to note that, according to Aquinas, not all absences of good are evil, although all evils are absences of some good. In this regard, he is careful to make a distinction between "negative" and "privative" absences of good. ${ }^{101}$ Aquinas explains:

Absence of good, taken negatively, is not evil; otherwise, it would follow that what does not exist is evil, and also that everything

99 Endel Tulving, "Memory and Consciousness," Canadian Psychology 26 (1985):

$1-12$, at 3.

100 ST I, q. 49, a. 1.

$101 S T$ I, q. 48, a. 3. See also Aquinas, De malo, q. 1, a. 2. 
would be evil, through not having the good belonging to something else.... For instance, a man would be evil who had not the swiftness of the roe, or the strength of a lion. But the absence of good, taken in a privative sense, is an evil; as, for instance, the privation of sight is called blindness. ${ }^{102}$

As can be seen in Aquinas's definition of evil, an absence of a good is evil only if the good is "natural and due" to a particular subject. For example, it would be an evil for a human to be blind because sight is something humans should possess according to their natures. But it would not be an evil for a rock to be blind, as rocks do not naturally possess the ability to see. ${ }^{103}$ The absence of sight in a human is a privation of a natural good, while the lack of sight in a rock is merely an absence of a good.

With this definition of evil in mind, it is clear that pain and suffering cannot be evils according to the Thomistic concept of "evil." The sensation of pain is thought to be a homeostatic emotion, similar to itching, hunger, and thirst. ${ }^{104}$ Without pain, the lifespan of humans and most nonhuman animals would be significantly shorter. ${ }^{105}$ It is no secret that the ability to feel pain is crucial for nonhuman animal flourishing. Additionally, researchers believe that other types of suffering, such as sadness, fear, and even depression, are likewise homeostatic emotional responses that are conducive to physical and social survival. ${ }^{106}$

It is easy to conclude that God, as the creator of all human and nonhuman life, intended for animals to possess the abilities to anoetically and noetically experience pain and suffering. He endowed his creatures with

102 ST I, q. 48 , a. 3.

103 ST I, q. 48, a. 5, ad 1.

104 See A. D. Craig, "A New View of Pain as a Homeostatic Emotion," Trends in Neurosciences 26 (2003): 303-7.

105 For example, see Elna M. Nagasako, Anne Louise Oaklander, and Robert H. Dworkin, "Congenital Insensitivity to Pain: An Update," Pain 101 (2003): 213-19.

106 For examples, see: Norbert Schwarz, "Warmer and More Social: Recent Developments in Cognitive Social Psychology," Annual Review of Sociology 24 (1998): 239-64, at 245; Dacher Keltner and Ann M. Kring, "Emotion, Social Function, and Psychopathology," Review of General Psychology 2 (1998): 320-342, at 324; Arne Öhman and Susan Mineka, "Fears, Phobias, and Preparedness: Toward an Evolved Module of Fear and Fear Learning," Psychological Review 108, no. 3 (2001): 483-522, at 483; and Nicholas B. Allen and Paul B. T. Badcock, "Darwinian Models of Depression: A Review of Evolutionary Accounts of Mood and Mood Disorders," Progress in Neuro-Psychopharmacology \& Biological Psychiatry 30 (2006): 815-26, at 819 . 
these homeostatic emotions so that they would flourish in their natural environments. ${ }^{107}$ In this way, pain and other forms of suffering are not evil, since God wills creatures to possess these metaphysically and instrumentally good abilities. Both humans and nonhuman animals experience pain and suffering, although nonhuman animals do not self-referentially experience pain and suffering.

\section{Suffering as the Privation of the Willed Good}

However, there is a particular sense in which Aquinas thought pain and suffering could be viewed as evils. For example in $S T$, he mentions that evils are rightly divided into two categories: evils of punishment and evils of fault. In describing evils of punishment, Aquinas says:

Intellectual creatures also suffer evil when they are deprived of forms or dispositions or anything else potentially necessary for good activity, whether the things belong to the soul or the body or external things. And such evil, in the judgment of the Catholic faith, needs to be called punishment.

For three things belong to the nature of a punishment. . . . The second characteristic of the nature of punishment is that it is contrary to the will of the one suffering punishment. For everyone's will inclines to seek the person's own good, and so it is contrary to one's will to be deprived of one's own good. ${ }^{108}$

Aquinas is here explaining that natural evils are rightly called punishments in humans because the deprivation of the form or disposition of a human is against the will. In other words, no human wants to experience natural evils in his own body. This would include the experience of pain and suffering because such things are unwanted and unpleasant and entail a loss of user control.

However, if nonhuman animals do not possess immaterial intellects and if all of their actions are determined by the laws of nature, then they cannot possess free will. Pain and suffering cannot be evils for them in the subjective sense, since they can neither understand that they are in pain

107 To be clear, I am not saying that pain and suffering are good in the sense that they ought to be sought for their own sakes. Instead, they are instrumental goods that help creatures flourish.

108 De malo, q. 1, a. 4, in Aquinas, On Evil, trans. Richard Regan, ed. Brian Davies (New York: Oxford University Press, 2003), 77. 
nor freely will to stop experiencing it. Of course, it may appear that they will to avoid pain as humans do, but they are not willing in a morally relevant sense, as their pain-avoidance behavior is due to lower-order processes and not the higher-order wish to avoid the lower-order suffering.

Thus, from a Thomistic perspective, animal pain and suffering are not evil. They are not intrinsically evil states because they are good physiological processes that are natural to nonhuman animals and necessary for flourishing. Also, they are not evil in that they are not experienced self-referentially by nonhuman animals and cannot be against the will of nonhuman animals, since nonhuman animals do not possess free will.

Before concluding, it will be good to note an interesting aspect of the neo-Thomistic answer to the problem of animal suffering. As the evidence suggests, it is most likely that nonhuman animals are neither rational nor self-aware. While there are a few promising candidates, such as dolphins, elephants, and great apes, the majority of nonhuman animals are not considered to be possibly self-conscious.

Yet if it were conclusively determined that one of these candidates were in fact self-aware, this would not overturn the neo-Thomistic answer to the problem of animal suffering. This is because, if it were determined that an animal is rational and self-aware, this would entail that the animal would possess a rational soul along with an immaterial intellect. The reason that it would not be problematic is that Aquinas believed that rational animals can survive the death of their bodies due to the immateriality of the intellect. ${ }^{109}$

Thus, if an animal were found to be rational and self-aware, it would follow that the animal could participate in the resurrection of the dead at the end of days. Since nonlinguistic animals do not know the difference between right and wrong and also could never understand the Gospel message, it is possible that they could live in the new heavens and new earth with human saints at the end of days. Thus, a relatively short life involving suffering would ultimately result in eternal life in the presence of God. The suffering of rational nonhuman animals (if such creatures were found to exist) would be allowed by God for the purpose of communicating his goodness. Perhaps God decided that the hierarchy of beings he creates to achieve his purpose should include rational nonhuman animals. ${ }^{110}$ So, even if a theist is in doubt as to the personhood of any

109 ST I, q. 75, a. 6; SCG II, ch. 79-81; Q.D. de anima, a. 14.

110 For a discussion of the Thomistic concepts of God's purpose for the universe, the necessity of a hierarchy of beings, what it means for God to "communicate his goodness," and what these entail for the problem of animal suffering, see B. Kyle 
particular animal, they can conclude that, if the animal is self-aware, the animal will ultimately experience a fate similar to that of humans who join God in eternity.

\section{Conclusion}

So it seems that the philosophy of Thomas Aquinas, along with contemporary philosophical and scientific evidence, provides a solution to the problem of animal suffering. Aquinas believed that the difference between human and nonhuman animals is that the former possess rational souls and the latter possess merely sensitive souls. As rational animals, humans possess immaterial intellects, which give them the abilities of rationality and self-awareness. The lack of an immaterial intellect makes it such that nonhumans animals are neither rational nor self-aware, and therefore lack moral agency and personhood.

Contemporary philosophical and scientific evidence supports Aquinas's medieval theory of animal minds. The evidence suggests that nonhuman animals are incapable of abstract reasoning and lack higher-order metacognitive abilities and episodic memory. Thus, nonhuman animals do not experience pain and suffering as persons. They do not have higher-order access to their lower-order mental states and they cannot self-referentially remember or anticipate painful experiences. Also, they cannot come to the understanding that they ought not be in pain.

It could be objected that this does not solve the problem, since animals are phenomenologically aware of pain and suffering. However, it was shown that this cannot be understood as evil because pain and suffering are metaphysically and instrumentally good physiological processes. So, pain and suffering are not evil because they are not privations of proper goods and are conducive to flourishing. Moreover, pain and other unpleasant states are not evils in nonhuman animals because nonhuman animals do not possess free will.

The evidence suggests that nonhuman animals are most likely not selfaware and that there is no problem of animal suffering. However, even if a certain kind of nonhuman animal were found to possess self-awareness, this would not eliminate the neo-Thomistic answer. Instead, all it would entail is that the certain kind of animal would most likely be rewarded with eternal life at the end of days. Thus, neo-Thomism not only provides an answer to the problem of animal suffering but also provides a more compelling answer than does neo-Cartesianism. Most researchers believe

Keltz, "God's Purpose for the Universe and the Problem of Animal Suffering," Sophia (2017): 1-18. 
that nonhuman animals are conscious, but few, if any, believe that nonhuman animals are self-aware like humans. 